\title{
Article \\ Advanced Tribological Characterization of DLC Coatings Produced by Ne-HiPIMS for the Application on the Piston Rings of Internal Combustion Engines
}

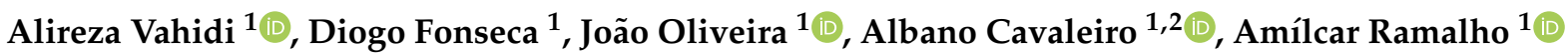 \\ and Fábio Ferreira $1, * \mathbb{D}$ \\ 1 Department of Mechanical Engineering, CEMMPRE, University of Coimbra, Rua Luis Reis Santos, \\ 3030-788 Coimbra, Portugal; alirezavahidi@hotmail.com (A.V.); diogofonseca28@gmail.com (D.F.); \\ joao.oliveira@dem.uc.pt (J.O.); albano.cavaleiro@dem.uc.pt (A.C.); amilcar.ramalho@dem.uc.pt (A.R.) \\ 2 LED\&Mat-IPN, Laboratório de Ensaios Desgaste e Materiais, Instituto Pedro Nunes, Rua Pedro Nunes, \\ 3030-199 Coimbra, Portugal \\ * Correspondence: fabio.ferreira@dem.uc.pt
}

\section{check for} updates

Citation: Vahidi, A.; Fonseca, D.; Oliveira, J.; Cavaleiro, A.; Ramalho, A.; Ferreira, F. Advanced Tribological Characterization of DLC Coatings Produced by Ne-HiPIMS for the Application on the Piston Rings of Internal Combustion Engines. Appl. Sci. 2021, 11, 10498. https://doi.org/ 10.3390/app112110498

Academic Editors: Mário Ferreirac and João Tedim

Received: 2 October 2021

Accepted: 4 November 2021

Published: 8 November 2021

Publisher's Note: MDPI stays neutral with regard to jurisdictional claims in published maps and institutional affiliations.

Copyright: (c) 2021 by the authors. Licensee MDPI, Basel, Switzerland. This article is an open access article distributed under the terms and conditions of the Creative Commons Attribution (CC BY) license (https:/ / creativecommons.org/licenses/by/ $4.0 /)$.
Featured Application: This work represented the real conditions of the lubricated contact between the piston rings and cylinder liners of internal combustion engines to prove that Diamond-like Carbon film deposited by Ne-HiPIMS technology can provide a major efficiency improvement if it is applied for piston rings instead of coatings like Chromium Nitride that are widely used.

Abstract: Piston rings (PR) are known for almost a quarter of the friction losses in internal combustion engines. This research work aims to improve the tribological performance of PR by a recently developed variant of Diamond-like Carbon (DLC) coatings deposited in a mixture of Ar and Ne plasma atmosphere (Ne-DLC) by high-power impulse magnetron sputtering (HiPIMS). For the benchmark, the widely used Chromium Nitride $(\mathrm{CrN})$ and DLCs deposited in pure Ar plasma atmosphere (Ar-DLC) were used. The tribological tests were performed on a block-on-ring configuration under different lubrication regimes by varying temperatures and sliding speeds. The analysis of the results was performed by Stribeck curves corresponding to each sample. An improvement of the tribological performance was observed for Ne-DLC films by up to $22.8 \%$ reduction in COF compared to CrN in the boundary lubrication regime, whereas, for the Ar-DLC film, this reduction was only 9.5\%. Moreover, the Ne-DLC films achieved ultralow friction of less than 0.001 during the transition to a hydrodynamic lubrication regime due to better wettability (lower contact angle) and higher surface free energy. Increasing the Ne up to $50 \%$ in the discharge gas also leads to an increase of hardness of DLC films from 19 to $24 \mathrm{GPa}$.

Keywords: piston rings; tribology; DLC; HiPIMS; neon; high temperature; Stribeck curves; hardness; contact angles

\section{Introduction}

The efficiency of an internal combustion engine (ICE) is an increasingly important concept nowadays, largely due to climate change and the need to reduce $\mathrm{CO}_{2}$ emissions into the atmosphere, trying, at all costs, to minimize the irreversible losses on our planet. Moreover, the efficiency of an ICE is also extremely important for the automotive industry, because the customers are looking for cars with less fuel consumption.

It is estimated that a piston ring (PR) is responsible for about $24 \%$ of the friction losses in an ICE [1]. In other words, half of the friction losses from power cylinders are generated by PRs [2]. In this way, inevitably, the performance of an ICE is directly linked to the coefficient of friction generated by the contact of the PR with the cylinder liner [3]. To reduce friction losses in PRs, studies have focused on the development of new materials, 
such as lubricants, surface textures or coatings to be applied to PRs, with the ability to reduce the coefficient of friction and improve the desired performance $[3,4]$.

As for coatings, developments have led to the frequent use of hard ceramic coatings deposited by Physical Vapor Deposited (PVD), such as CrN, as it combines satisfactory tribological properties with high hardness, and corrosion resistance at high temperatures, with low production costs, which is a determinant for large-scale applications [5].

Recently, improvements in tribological properties have been achieved with the development of a new coating, Diamond-like Carbon (DLC). It is considered one of the best coating materials for the application in the automotive industry, as it contains smoother surfaces, has higher hardness, and at the same time, presents improvements in tribological properties, namely regarding the coefficient of friction, with significantly lower values than $\mathrm{CrN}$ [6].

However, the main challenge in applying DLC coatings in the engines is to assess their reactions to recent developments, such as turbocharging and downsizing. These developments have led to the need for the use of increasingly higher operating temperatures [7]. Therefore, DLC coatings that are more stable at high temperatures, such as hydrogen-free tetrahedral amorphous carbon $(\operatorname{ta}-\mathrm{C})$, are demanding. One of the techniques used for the deposition of ta-C coatings is cathodic arc deposition, which is a highly ionized PVD technique. The drawback of this technique is macroparticles that are ejected during the deposition from the target that is applied for this technique. The way to get around this problem is by filtering the generated plasma; however, its high cost, together with the lower deposition ratio, make this filtering process not the way to follow. Moreover, the major limitation in the deposition of the ta-C coatings is the maximum thickness limits due to the development of internal stresses during their depositions [8].

Another technique of deposition of DLC by PVD is direct current magnetron sputtering (DCMS). This technique can be used to obtain DLC films with smooth surfaces, controlling their roughness through atomic deposition. Although it is possible to control the surface roughness of the film, the main disadvantage compared to the previous technique (cathodic arc deposition) is the production of films with lower hardness, as well as lower density $\left(1.8-2.3 \mathrm{~g} / \mathrm{cm}^{3}\right)$ [9].

With the development and research of new technologies for the deposition of DLC films, promoting the best possible tribological and mechanical properties, high-power impulse magnetron sputtering (HiPMS) has emerged. This new technique quickly attracted the attention of researchers for its use in hard DLC films, as it provides an increase in the density of the deposition plasma compared to the previously used technique (DCMS) [10]. This technique has been successfully implemented for elements with ionization energies between 6 and $8 \mathrm{eV}$ [11], such as Al, Ti, Cr, Ag, etc. [12]. However, the standard HiPIMS does not provide enough effectiveness for elements with higher ionization energies, such as carbon (11.6 eV), and lower ionization cross-section [13]. In 2012, Aijaz et.al proposed a strategy to use the HiPIMS process to increase the electron temperature, then increase the mass density of the films (up to $2.8 \mathrm{~g} / \mathrm{cm}^{3}$ ). This strategy involved adding $\mathrm{Ne}$ to the atmosphere used for the depositions, which, until then, only contained Ar. Since $\mathrm{Ne}$ has higher ionization energy than $\mathrm{Ar}, 21.56 \mathrm{eV}$, and $15.5 \mathrm{eV}$, respectively [14], with the introduction of $\mathrm{Ne}$ in the deposition plasma, it is possible to increase the temperature of the electrons and the ionization fraction of the ionized carbon species. Several researchers have reported that the mixture of gases in the plasma atmosphere, $\mathrm{Ar}+\mathrm{Ne}$, or even the total replacement of Ar by Ne resulted in significant improvements in the mechanical and tribological properties of DLC coatings $[15,16]$.

In previous work, the authors showed that adding Ne to the discharge gas of the recently developed variant of HiPIMS, called deep oscillation magnetron sputtering (DOMS), leads to the deposition of DLC films with a better tribological performance in the boundary lubrication regime at room temperature [17].

The present research work has as an objective to characterize the tribological performance of DLC coatings produced by Ne-HiPIMS, which are called Ne-DLC in this 
work, under different lubrication regimes at room and high temperatures. The elaborated counter body for the tribological tests was grey cast iron (typical material for cylinder liners), intended to compare the effectiveness in reducing the coefficient of friction between Ne-DLC films produced in a mixture of exhaust gases ( $\mathrm{Ar}+\mathrm{Ne}$ ) with DLC films produced in pure $\mathrm{Ar}(\mathrm{Ar}-\mathrm{DLC})$ in the discharge gas and a $\mathrm{CrN}$ coating film.

\section{Materials and Methods}

For this research work, steel substrates (AISI D2) with the dimensions of $25 \mathrm{~mm}$ in diameter and a thickness of $8 \mathrm{~mm}$ were used to deposit the films. Before the depositions, the substrates were mirror-polished and cleaned with ethanol and acetone in an ultrasonic bath lasting $15 \mathrm{~min}$ each. Once the preparation of the substrates was finished, they were glued using thermal and electric conductive silver glue onto an aluminum substrate holder rotating with a constant speed of $23.5 \mathrm{rpm}$ around the central axis of the deposition chamber during the depositions. The distance between the substrates and the targets was $80 \mathrm{~mm}$ in the deposition chamber. A rotary and turbomolecular pump was used to reach the base pressure of below $3 \times 10^{-4}$ Pa before the depositions. To clean the surfaces of the substrates and, consequently, enhance the adhesion, etching treatment was applied by ion gun with a voltage and current of $36 \mathrm{~V}$ and $20 \mathrm{~A}$, respectively, when a bias of $-150 \mathrm{~V}$ was used for the substrates for $40 \mathrm{~min}$. To further improve the adhesion of the DLC films to the substrates, a Cr adhesion layer was deposited by DCMS (Huttinger PFG 7500 DC, Ditzingen, Germany) in pure Ar plasma at the pressure of $0.8 \mathrm{~Pa}$ and $-80 \mathrm{~V}$ of substrate biasing, and it was followed by the deposition of the $\mathrm{CrN}$ supporting layer that was deposited when introducing an $\mathrm{N}_{2}$ content of $33 \%$ in the discharge gas and the same deposition conditions as the $\mathrm{Cr}$ deposition.

To deposit DLC films, a graphite (99.95\%) target with dimensions of $150 \times 150 \times 10 \mathrm{~mm}$ was used in the $\mathrm{Ar}$ and $\mathrm{Ar}+\mathrm{Ne}$ discharge gases at $0.8 \mathrm{~Pa}$ by DOMS (HIPIMS, Zpulser Inc., Mansfield, MA, USA), with the following parameters: ton $=6 \mu \mathrm{s}, \mathrm{T}=130 \mu \mathrm{s}, \mathrm{D}=1690 \mu \mathrm{s}$ and average power $\left(\mathrm{P}_{\mathrm{a}}\right)$ equal to $1.3 \mathrm{KW}$.

In this work, three distinct DLC coatings were produced. One DLC film was deposited using pure Ar plasma. For the deposition of the other two DLC films, before ignition of the plasma, Ne was introduced to the discharge gas with contents of $25 \%$ and $50 \%$ simultaneously, with reducing the Ar flux to maintain the deposition pressure at $0.8 \mathrm{~Pa}$. In Table 1, the respective deposition conditions for the DLC coatings are presented. A CrN coating was deposited for comparison purposes by using the mentioned DCMS power supply with a power of $1.2 \mathrm{KW}$ in the $\mathrm{Ar}+\mathrm{N}_{2}$ discharge gas that had a flow rate of 68 SCCM (flow ratio of Ar: $\mathrm{N}_{2}$ was equal to 1:3) with a pressure of $0.3 \mathrm{~Pa}$.

Table 1. Deposition conditions for the DLC films.

\begin{tabular}{cccccc}
\hline Pressure & $\mathbf{N e}$ & $\mathbf{V}_{\mathbf{p}}$ & $\mathbf{I}_{\mathbf{p}}$ & $\mathbf{P}_{\mathbf{p}}$ & $\mathbf{F}_{\mathbf{i}}$ \\
\hline$(\mathrm{Pa})$ & $(\%)$ & $(\mathrm{V})$ & $(\mathrm{A})$ & $(\mathrm{KW})$ & $(\mathrm{Hz})$ \\
\hline 0.8 & 0 & 1384 & 76.1 & 105 & 247 \\
\hline & 25 & 1365 & 90 & 123 & 261 \\
\hline & 50 & 1349 & 96 & 130 & 266 \\
\hline
\end{tabular}

For tribological testing, a block on the ring assembly was used (Figure 1); more details are presented in Reference [18]. The principle of this test consists of placing a sample (coated substrate) in contact $\left(90^{\circ}\right.$ in relation to the geometric center of the ring) with the outer surface of the ring. In this assembly, there are two load cells, one working as the input (normal force cell, $\mathrm{F}_{\mathrm{N}}$ ) and another as the output, where the friction force $\left(\mathrm{F}_{\mathrm{f}}\right)$ is measured (tangential force cell), which, by dividing $\mathrm{F}_{\mathrm{f}}$ by $\mathrm{F}_{\mathrm{N}}$, the coefficient of friction $(\mu)$ is obtained. 


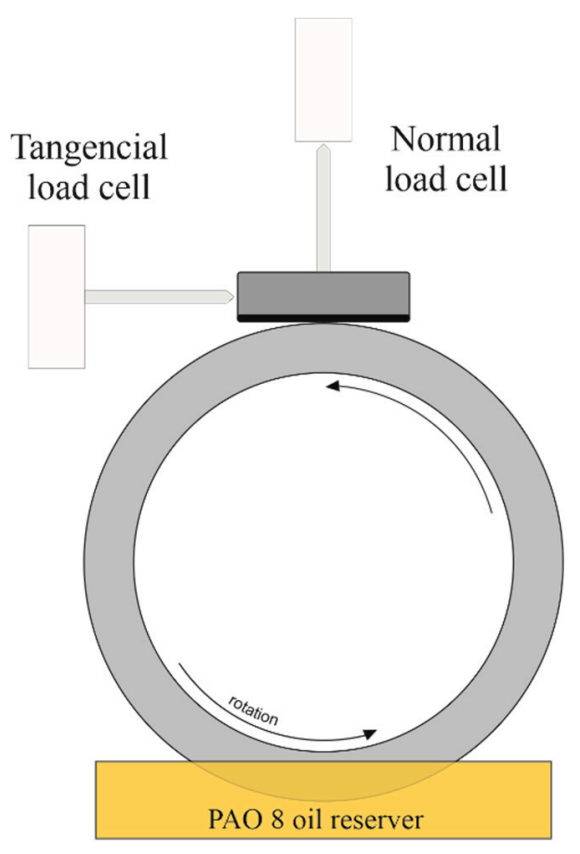

Figure 1. Schematic diagram of the block-on-ring sliding test tribometer.

In this assembly, there is a lubricant reservoir for keeping the contact lubricated with the lubricating oil. The counter body is a grey cast iron EN GJL-300 ring (typical material used in cylinder liners) with the dimensions of $\varnothing 116 \times 12 \mathrm{~mm}$. To approximate as closely as possible the working conditions existing in ICE, the ring was honed on the outer surface to ensure lubricated contact with PR [19]. To perform the honing, the surface was scratched in two different directions using 320 granulometry sandpaper, creating geometric shapes identical to the diamond. After the previous procedure was completed, the surface was polished with 600 and 1000 granulometry sandpaper, and the roughness was determined using a profilometer. To finish the honing, it was necessary to remove the peaks created when using the sandpaper, leaving the valleys to ensure that the ring always contains lubricating oil in its rotational movements. In this way, it was necessary to again use sandpaper 1000 granulometry (standard parameters used in CEMMPRE Laboratory). The polishing of the surface is necessary to carefully observe its microstructure. For that, its cross-section is observed (cutting a small section of the ring, wetting it in acrylic resin, and drying it so that the surfaces are parallel and flat), polishing it with diamond paste $(3 \mu \mathrm{m})$. All this process is done under an optical microscope $(1000 \times$ magnification) after revealing the structure using $2 \%$ Nital etchant.

Since the objective of this work was to study the tribological properties of the coatings, it was necessary to use a base lubricating oil, free of additives such as friction modifiers, for a better understanding of the real role of the coatings. In addition, although the contact between the piston ring and cylinder liner is mostly governed by hydrodynamic and mixed lubrication regimes in the internal combustion engines [20], when the piston ring hits the top dead center of the stroke, the contact is in the boundary lubrication regime where the role of the coatings matters [21]. Therefore, Polyalphaolefin (PAO) 8 base oil was chosen as the lubricating oil for this study because it is used as the base oil for some of the commercial engine oils [22].

The tests were performed using different speeds (Table 2) at 250 revolutions of the ring, which was enough to reach the stationary friction regime. For temperature control during the tests, a radiation heating system was used to heat the ring. In this way, it was possible to carry out the tests at different high temperatures in the oil as well, which were 60,80 , and $100^{\circ} \mathrm{C}$ in this study, based on the fact that the oil temperature in the operating conditions in an engine varies from less than $60^{\circ} \mathrm{C}$ to a maximum of $104{ }^{\circ} \mathrm{C}$ [23]. The viscosity-temperature curve was determined by using the viscometer (A\&D, SV-10 model, 
Tokyo, Japan). To do that, the oil was heated up to $100{ }^{\circ} \mathrm{C}$ by the oven (JP-SELECTA, DIGITHEAT model, Barcelona, Spain) before starting to measure the viscosity when the oil was cooled down naturally to room temperature.

The surface wettability of the films was assessed by measuring the contact angle of a drop of lubricating oil (PAO 8) on the dried and cleaned surface of the films at room temperature $\left(25^{\circ} \mathrm{C}\right)$. Following that, the surface free energy of the films was measured by substituting the values of contact angle in Young's equation [24]. The hardness of the films was measured by nanoindentation (MicroMaterials NanoTest, Wrexham, UK) using a Berkovich diamond indenter. Sixteen hardness measurements were performed for each specimen at different points. A $10-\mathrm{mN}$ load was used to ensure an indentation depth lower than $10 \%$ of the coating's thickness.

Table 2. Sliding speeds that were applied for the tests in the angular (rpm) and linear (m/s) speeds.

\begin{tabular}{ccccccccccc}
\hline $\mathrm{rpm}$ & 4.6 & 5.4 & 7.7 & 12 & 17 & 30 & 45 & 70 & 100 & 130 \\
\hline $\mathrm{m} / \mathrm{s}$ & 0.028 & 0.033 & 0.047 & 0.073 & 0.103 & 0.182 & 0.273 & 0.425 & 0.607 & 0.7790 \\
\hline
\end{tabular}

\section{Results and Discussion}

\subsection{Counter Body Characterization}

The characterization of the counter body material is extremely important for a deeper understanding of the tribological properties. The knowledge of the material used in both bodies, as well as their performances, gives the necessary proportions for this study. Grey cast iron is known for its good tribological characteristics, particularly in wear resistance and the low friction values generated, which has been the choice of manufacturers for the material to be used in cylinder liners. The microstructure of this material has some ferrite regions and a graphite flake structure within a pearlite matrix. The grey cast iron's maximum hardness can reach $250 \mathrm{HV}$ ( $2.45 \mathrm{GPa})$ [25], which is much lower in comparison with the hardness of the coatings presented in this work. However, the presence of graphite in the microstructure of this material works as a solid lubricant. Thus, it forms a layer of graphite on the surfaces of both bodies, removed from the microstructure of grey cast iron, acting as a lubricant at the time of contact. The chemical composition of the counter body is presented in Table 3. Noting that, in the chemical composition, there are elements of magnesium and sulfur, which are from magnesium sulfate inclusions that were formed while machining grey cast iron. These inclusions present on the matrix also actuate as solid lubricants help to improve the tribological properties of the material during its service even more $[26,27]$.

Table 3. Chemical elements table of grey cast iron EN GJL-300.

\begin{tabular}{cccccccc}
\hline Element & $\mathrm{C}$ & $\mathrm{Si}$ & $\mathrm{Mn}$ & $\mathrm{S}$ & $\mathrm{P}$ & Others & $\mathrm{Fe}$ \\
\hline Typical & $2.95-3.45$ & $2.1-2.9$ & $0.55-0.75$ & $0.04-0.07$ & $0.1-0.2$ & Residual & Balance \\
\hline
\end{tabular}

\subsection{Lubricant Viscosity}

The viscosity is one of the most important parameters in lubricated contacts, as it can determine the tribological properties of the lubricants [28]. Viscosity is a variable parameter in this study since different temperatures were applied for the tests. Figure 2 shows the variations of the viscosity of PAO 8 oil with the temperature changes. Comparing the viscosity of this oil with the commercial engine oil (SAE 10W-40) used in the previous work [17], it was observed that PAO 8 oil has a much lower viscosity in all temperatures. This proves that PAO 8 oil is more suitable for this study to ensure contact in the boundary lubrication regime at higher temperatures. 


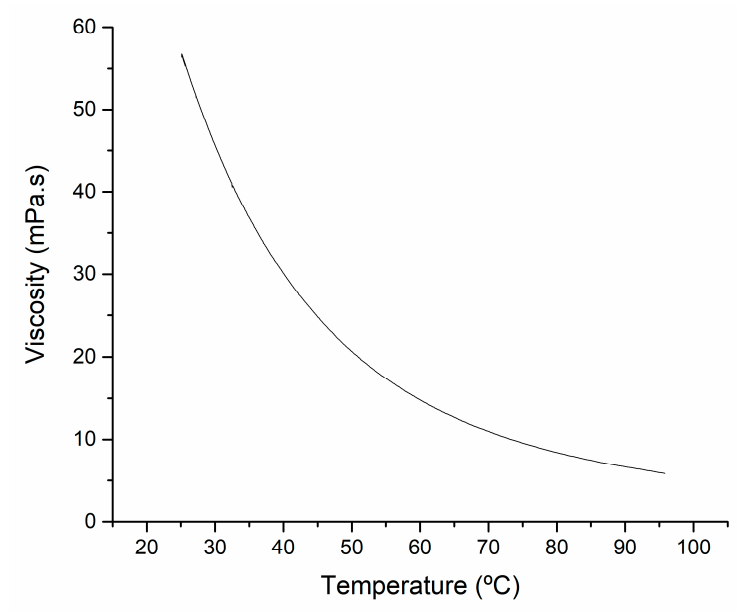

Figure 2. Viscosity-temperature graph for PAO 8 oil.

As the tests were performed at four distinct temperatures, it is essential to calculate the viscosity at these temperatures. The equation that was obtained from the viscositytemperature curve in Figure 2 can be expressed as Equation (1):

$$
\eta=\exp [(T-136.05) /-27.58]
$$

where $\mathrm{T}$ is the temperature, and $\eta$ is the dynamic viscosity of the lubricant at the specified temperature.

Table 4 shows the calculated values, using Equation (1) for the viscosity at the temperatures that the tests were performed.

Table 4. Viscosity values for the different temperatures used for the tests lubricated with PAO 8.

\begin{tabular}{cccccc}
\hline Temp. & $\left({ }^{\circ} \mathrm{C}\right)$ & 25 & 60 & 80 & 100 \\
\hline Viscosity & (mPa.s) & 56.063 & 15.579 & 7.632 & 3.695 \\
\hline
\end{tabular}

\subsection{Stribeck Curves}

The Hersey parameter was calculated by the viscosity of the lubricating oil at different temperatures (Table 4) times the applied sliding speed during the tests and divided by the normal force that is the only constant parameter in this study. This was not completely right, as there was always some variation in the normal load during the tests due to residual misalignment of the external surface of the ring. This residual misalignment was so insignificant that the normal load was considered constant.

Figure 3 shows the Stribeck curves that were obtained by the values of the coefficient of friction from the different tests performed at distinct speeds and temperatures for different coating films. The standard deviation values were very small for all points and tended to decrease with increasing the sliding speed; hence, only the average data set was demonstrated. By analyzing these curves, three lubrication regimes could be obtained, which were the boundary, mixed and hydrodynamic lubrication. The hydrodynamic lubrication occurred at a higher sliding speed and viscosity of the lubricant at lower temperatures. As the temperature of the tests increased, and the sliding speed decreased, and the lubrication regime shifted to mixed lubrication, where the coefficient of friction started to increase due to the mechanical contact of higher asperities caused by the lower thickness of the lubricant film. Finally, it reached the boundary lubrication regime, which occurred at lower sliding speeds and the viscosity of the lubricant at higher temperatures. In this regime, the mechanical contact of the asperities was promoted, and the thickness of the lubricant could not overcome the roughness of the contact surfaces; hence, the coefficient of friction significantly increased. 


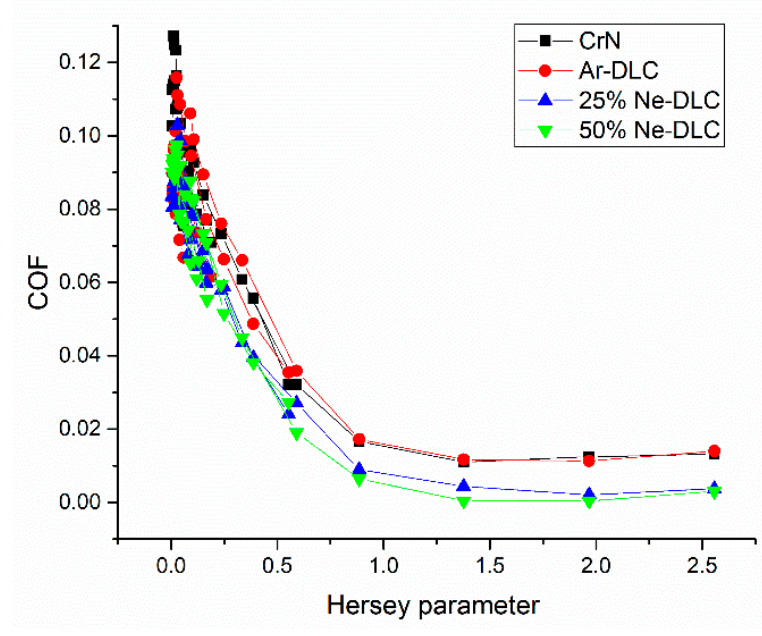

Figure 3. Stribeck curves for the lubricated contacts in the block-on-ring tests.

Comparing the Stribeck curves for different films showed that DLC films have a lower COF compared to $\mathrm{CrN}$ in the boundary lubrication regime due to their smoother surface. However, the reduction of COF compared to $\mathrm{CrN}$ was $9.5 \%$ for the Ar-DLC film, whereas, for the Ne-DLC films, this reduction reached $22.8 \%(\mathrm{COF}<0.1)$ compared to $\mathrm{CrN}$. By increasing the Hersey parameter and approaching the mixed and hydrodynamic lubrication regimes, the values of COF for Ar-DLC and $\mathrm{CrN}$ were close to each other, but for the Ne-DLC films, the value of COF was still much lower in these regimes, achieving ultralow friction of less than 0.001 , which can be a major efficiency improvement in contact between the PR and cylinder liner. This means adding Ne to the plasma not only caused the deposition of DLC films with lower COF in the boundary lubrication regime but also caused a better tribological behavior in the mixed and hydrodynamic lubrication regimes, where the amount of friction was determined mostly by the lubricant. Therefore, this was related to solid-liquid interfacial properties, which are vital for lubricated contacts, and they will be discussed in detail in the next section.

\subsection{Wettability and Surface Free Energy}

As it was discussed in the previous section, the study of solid-liquid interfacial properties is required to understand the tribological behavior in mixed and hydrodynamic lubrication regimes. Two of the most common interface properties are wettability and surface free energy, which are evaluated and calculated by contact angle measurements. Since, in this study, the lubricant that was used for the tests was PAO 8 oil, the contact angle measurements were carried out by using this oil as well. In short, the tests were performed by freely releasing an oil drop onto the surfaces of the coatings and checking how it spread over a certain period of time, which, in this study, was $0.06 \mathrm{~s}$. Figure 4 shows the images taken at $0.06 \mathrm{~s}$ after the oil drop came into contact with the surfaces of the coating films and the values of the angles for one of the examples of each film contact angle measurement with PAO 8 oil. 

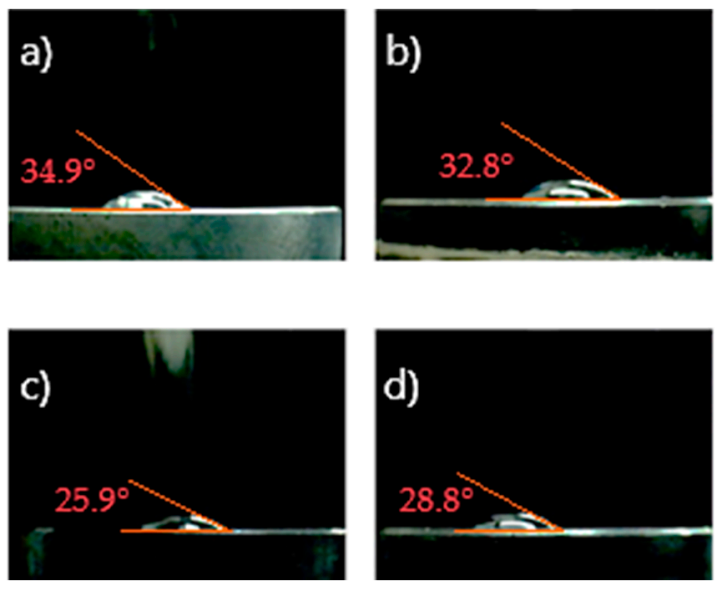

Figure 4. Drops of PAO 8 oil snapshots at 0.06 s on the surfaces: (a) $\mathrm{CrN}$, (b) Ar-DLC, (c) 25\% Ne-DLC and (d) $50 \%$ Ne-DLC.

A graph is presented with the measured contact angles values in Figure 5. Lower contact angle values mean that the lubricant tends to spread and adhere to the surface (better surface wettability), whereas higher contact angle values show the surface's tendency to repel the lubricant. On the other hand, surface free energy determines the strength of the interactions that the surface forms with the lubricant. Therefore, increasing the surface free energy of the coatings means the lubricant flows out more on the surface of the coatings and causes better tribological performance in the lubricated contacts. Observing Figure 5, it can be seen that the contact angles are much lower, and the surface energy is higher for Ne-DLC films compared to the Ar-DLC and CrN films. These results are in correlation with the Stribeck curves of the films since they also showed values of COF for the Ne-DLC films in the mixed and hydrodynamic lubrication regimes that were much lower than Ar-DLC and $\mathrm{CrN}$, which means the lubricant had better spreading and adhesion to their surfaces, which caused them to have better performances in these regimes.

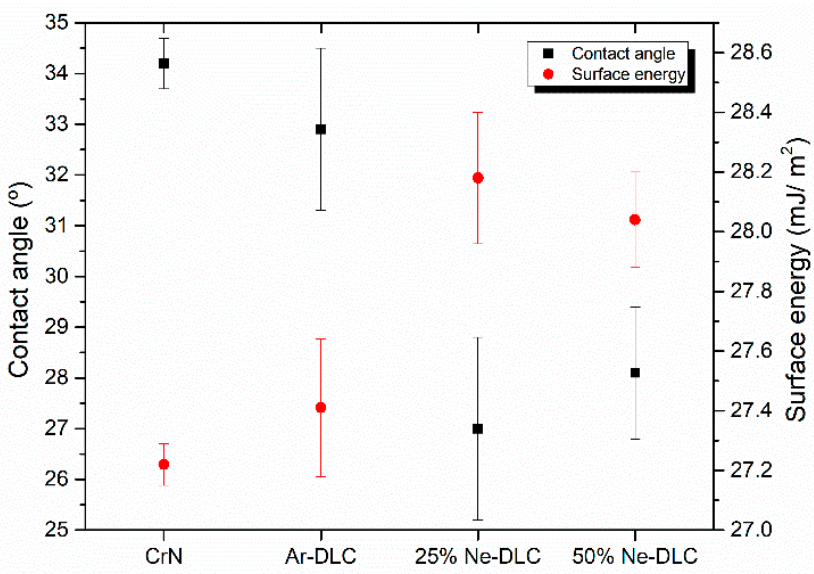

Figure 5. Contact angle measurements and surface free energy of the coating films.

\subsection{Hardness}

The hardness is a mechanical property that is closely related to the wear resistance of the films. Figure 6 shows the hardness of the films obtained by nanoindentation tests. The results of hardness for the DLC films were increased from almost 19 to 24 GPa by increasing the Ne percentage to $50 \%$ in the discharge gas, which was due to the deposition of a higher amount of $\mathrm{sp}^{3}$ carbon when $\mathrm{Ar}$ was partially replaced by $\mathrm{Ne}$ in the discharge gas [14]. This showed that the $50 \%$ Ne-DLC film not only had the lowest COF in the Stribeck curves, but it also had the highest hardness; hence, it was expected that this film also had a better wear 
resistance in comparison with the other films. On the other hand, the hardness of $\mathrm{CrN}$ was also high (20 GPa), but it had much less wear resistance in comparison with the DLC films, as was reported in the previous work [17]. This can be due to the high COF of the CrN film that resulted in higher wear rates in comparison to the DLC films, despite having a similar hardness value [29].

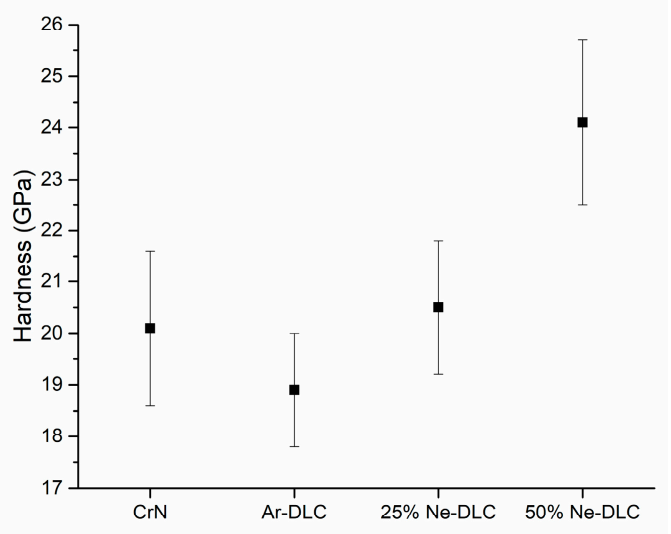

Figure 6. The hardness values of the coating films by nanoindentation.

\section{Conclusions}

The tribological performance of the DLC and CrN films in the lubricated contact was evaluated. The results showed that DLC films have a lower COF in comparison with the $\mathrm{CrN}$ film in the boundary lubrication regime due to their smoother surfaces. For the Ar-DLC coating, a reduction of $9.5 \%$, and, for the Ne-DLC films, a significantly higher reduction of 22.8\%, were observed in COF compared to CrN. Moreover, the Ne-DLC films had much better wettability and higher surface free energy, which led to a much better tribological behavior in the mixed and hydrodynamic lubrication regimes and achieved a COF value of less than 0.001 . In addition, substituting Ar by Ne up to $50 \%$ in the discharge gas increased the hardness of the films from 19 to 24 GPa by the deposition of DLC films with more sp3 carbon.

Finally, this research showed that applying Ne-HiPIMS technology led to the deposition of the DLC films with much better tribological and mechanical properties in comparison with the conventional DLC films. Therefore, if they are applied for PR coating as a replacement for $\mathrm{CrN}$, which is widely used in the automotive industry, there will be a major efficiency improvement in ICEs.

Author Contributions: Conceptualization, F.F.; methodology, F.F. and A.R.; validation, F.F. and A.R.; formal analysis, A.V. and D.F.; investigation, A.V. and D.F.; resources, A.C. and J.O.; data curation, A.V. and D.F.; writing-original draft preparation, A.V. and D.F.; writing-review and editing, F.F. and A.R.; supervision, F.F. and A.R.; project administration, J.O. and funding acquisition, A.C. and J.O. All authors have read and agreed to the published version of the manuscript.

Funding: This research was sponsored by national funds through FCT-Fundação para a Ciência e a Tecnologia under the projects UIDB/00285/2020 and HardRings (AAC n. ${ }^{\circ} 02 /$ SAICT / 2017, projeto n. $\left.{ }^{\circ} 29122\right)$.

Institutional Review Board Statement: Not applicable.

Informed Consent Statement: Not applicable.

Data Availability Statement: Not applicable.

Conflicts of Interest: The authors declare no conflict of interest. 


\section{References}

1. Tung, S.C.; Tseregounis, S.I. An investigation of tribological characteristics of energy-conserving engine oils using a reciprocating bench test. No. 2000-01-1781. In SAE Technical Paper; SAE International: Warrendale, PA, USA, 2000. [CrossRef]

2. Smedley, G. Piston Ring Design for Reduced Friction in Modern Internal Combustion Engines. Ph.D. Thesis, Massachusetts Institute of Technology, Cambridge, MA, USA, 2004.

3. Haque, T.; Morina, A.; Neville, A. Influence of friction modifier and antiwear additives on the tribological performance of a non-hydrogenated DLC coating. Surf. Coat. Technol. 2010, 204, 4001-4011. [CrossRef]

4. Lin, J.; Moore, J.J.; Sproul, W.D.; Mishra, B.; Wu, Z.; Wang, J. The structure and properties of chromium nitride coatings deposited using dc, pulsed dc and modulated pulse power magnetron sputtering. Surf. Coat. Technol. 2010, 204, 2230-2239. [CrossRef]

5. Ferreira, R.; Carvalho, Ó.; Sobral, L.; Carvalho, S.; Silva, F. Influence of morphology and microstructure on the tribological behavior of arc deposited CrN coatings for the automotive industry. Surf. Coat. Technol. 2020, 397, 126047. [CrossRef]

6. Fontaine, J.; Donnet, C.; Erdemir, A. Fundamentals of the Tribology of DLC Coatings. In Tribology of Diamond-Like Carbon Films; Springer: Boston, MA, USA, 2008; pp. 139-154. [CrossRef]

7. Holmberg, K.; Andersson, P.; Erdemir, A. Global energy consumption due to friction in passenger cars. Tribol. Int. 2012, 47, 221-234. [CrossRef]

8. Ferrari, A.C.; Kleinsorge, B.; Morrison, N.A.; Hart, A.; Stolojan, V.; Robertson, J. Stress reduction and bond stability during thermal annealing of tetrahedral amorphous carbon. J. Appl. Phys. 1999, 85, 7191-7197. [CrossRef]

9. Grill, A. Diamond-like carbon: State of the art. Diam. Relat. Mater. 1999, 8, 428-434. [CrossRef]

10. Santiago, J.A.; Fernández-Martínez, I.; Kozák, T.; Capek, J.; Wennberg, A.; Molina-Aldareguia, J.M.; Bellido-González, V.; González-Arrabal, R.; Monclús, M.A. Fundamentals of the Tribology of DLC Coatings. Surf. Coat. Technol. 2019, 358, 43-49. [CrossRef]

11. Helmersson, U.; Lattemann, M.; Bohlmark, J.; Ehiasarian, A.P.; Gudmundsson, J.T. Ionized physical vapor deposition (IPVD): A review of technology and applications. Thin Solid Film. 2006, 513, 1-24. [CrossRef]

12. Samuelsson, M.; Lundin, D.; Jensen, J.; Raadu, M.A.; Gudmundsson, J.T.; Helmersson, U. On the film density using high power impulse magnetron sputtering. Surf. Coat. Technol. 2010, 205, 591-596. [CrossRef]

13. Sarakinos, K.; Braun, A.; Zilkens, C.; Mráz, S.; Schneider, J.; Zoubos, H.; Patsalas, P. Exploring the potential of high power impulse magnetron sputtering for growth of diamond-like carbon films. Surf. Coat. Technol. 2012, 206, 2706-2710. [CrossRef]

14. Aijaz, A.; Sarakinos, K.; Lundin, D.; Brenning, N.; Helmersson, U. A strategy for increased carbon ionization in magnetron sputtering discharges. Diam. Relat. Mater. 2012, 23, 1-4. [CrossRef]

15. Aijaz, A.; Ferreira, F.; Oliveira, J.; Kubart, T. Mechanical Properties of Hydrogen Free Diamond-Like Carbon Thin Films Deposited by High Power Impulse Magnetron Sputtering with Ne. Coatings 2018, 8, 385. [CrossRef]

16. Bobzin, K.; Brögelmann, T.; Kalscheuer, C.; Engels, M. Synthesis of a-C coatings by HPPMS using Ar, Ne and He as process gases. Surf. Coat. Technol. 2016, 308, 80-89. [CrossRef]

17. Cardoso, F.; Ferreira, F.; Cavaleiro, A.; Ramalho, A. Performance of diamond-like carbon coatings (produced by the innovative Ne-HiPIMS technology) under different lubrication regimes. Wear 2021, 477, 203775. [CrossRef]

18. Vilhena, L.M.; Ramalho, A.; Cavaleiro, A. Grooved surface texturing by electrical discharge machining (EDM) under different lubrication regimes. Lubr. Sci. 2017, 29, 493-501. [CrossRef]

19. Mansori, M.E.; Goeldel, B.; Sabri, L. Performance impact of honing dynamics on surface finish of precoated cylinder bores. Surf. Coat. Technol. 2013, 215, 334-339. [CrossRef]

20. Pusterhofer, M.; Summer, F.; Wuketich, D.; Grün, F. Development of a Model Test System for a Piston Ring/Cylinder Liner-Contact with Focus on Near-to-Application Seizure Behaviour. Lubricants 2019, 7, 104. [CrossRef]

21. Bolander, N.W.; Steenwyk, B.D.; Sadeghi, F.; Gerber, G.R. Lubrication regime transitions at the piston ring-cylinder liner interface. Proc. Inst. Mech. Eng. Part J J. Eng. Tribol. 2005, 219, 19-31. [CrossRef]

22. ExxonMobil Spectrasyn ${ }^{\mathrm{TM}} 2$ Polyalphaolefin (PAO) Fluid Datasheet. Available online: http://www.lookpolymers.com/pdf/ ExxonMobil-SpectraSyn-2-Polyalphaolefin-PAO-Fluid.pdf (accessed on 29 October 2021).

23. Arai, K.; Yamada, M.; Asano, S.; Yoshizawa, S.; Ohira, H.; Hoshino, K.; Ueda, F.; Akiyama, K. Lubricant Technology to Enhance the Durability of Low Friction Performance of Gasoline Engine Oils. In SAE Technical Paper; SAE International: Warrendale, PA, USA, 1995; pp. 1964-1972. [CrossRef]

24. Kwok, D.Y.; Neumann, A.W. Contact angle interpretation in terms of solid surface tension. Colloids Surf. A Physicochem. Eng. Asp. 2000, 161, 31-48. [CrossRef]

25. Bahari, A.; Lewis, R.; Slatter, T. Hardness characterisation of grey cast iron and its tribological performance in a contact lubricated with soybean oil. Proc. Inst. Mech. Eng. Part C J. Mech. Eng. Sci. 2016, 232, 190-203. [CrossRef]

26. Evans, R. Selection and testing of metalworking fluids. In Metalworking Fluids (MWFs) for Cutting and Grinding; Woodhead Publishing: Cambridge, UK, 2012; pp. 23-78. [CrossRef]

27. Gundlach, R.; Meyer, M.; Winardi, L. Influence of Mn and S on the Properties of Cast Iron Part III-Testing and Analysis. Int. J. Met. 2015, 9, 69-82. [CrossRef] 
28. Mu, L.; Wu, J.; Matsakas, L.; Chen, M.; Vahidi, A.; Grahn, M.; Rova, U.; Christakopoulos, P.; Zhu, J.; Shi, Y. Lignin from Hardwood and Softwood Biomass as a Lubricating Additive to Ethylene Glycol. Molecules 2018, 23, 537. [CrossRef] [PubMed]

29. Ferreira, F.; Serra, R.; Cavaleiro, A.; Oliveira, J. Diamond-like carbon coatings deposited by deep oscillation magnetron sputtering in Ar-ne discharges. Diam. Relat. Mater. 2019, 98, 107521. [CrossRef] 